\title{
Production of English final stops by Korean speakers
}

\author{
Kim, Jungyeon*
}

\begin{abstract}
This study reports on a production experiment designed to investigate how Korean speaking learners of English produce English forms ending in stops. In a repetition experiment, Korean participants listened to English nonce words ending in a stop and repeated what they heard. English speakers were recruited for the same task as a control group. The experimental result indicated that the transcriptions of the Korean productions by English native speakers showed vowel insertion in only $3 \%$ of productions although the pronunciation of English final stops showed that noise intervals after the closure of final stops were significantly longer for Korean speakers than for English speakers. This finding is inconsistent with the loanword data where $49 \%$ of words showed vowel insertion. It is also not compatible with the perceptual similarity approach, which predicts that because Korean speakers accurately perceive an English final stop as a final consonant, they will insert a vowel to make the English sound more similar to the Korean sound.
\end{abstract}

Keywords: L2 speech production, adaptation, unnecessary repair, stop release

\section{Introduction}

It has been observed that when an English word ending in a stop is adapted to Korean, Korean speakers often insert a vowel after the final stop (e.g., rope $\rightarrow\left[\operatorname{lop}^{\mathrm{h}} \mathrm{i}\right], \mathrm{knit} \rightarrow\left[\operatorname{nit}^{\mathrm{h}} \mathrm{i}\right]$, peak $\rightarrow\left[\right.$ pik $\left.^{\mathrm{h}} \mathrm{i}\right]$ ). This vowel insertion is interesting since native Korean words may end in stops (e.g., /pap/ $\rightarrow$ [pap'] 'meal', /kot/ $\rightarrow\left[\mathrm{kot}^{\top}\right]$ 'soon', $/ \mathrm{mok} / \rightarrow\left[\mathrm{mok}^{\prime}\right]$ 'neck'). Thus, the original foreign forms ending in a stop would be pronounceable in Korean. This vowel insertion has been referred to as unnecessary repair by Peperkamp (2005), where a foreign structure is changed even when the original structure would have been legal in the recipient language (Golston \& Yang, 2001; Kang, 2003; Peperkamp, 2005).

Previous studies have focused mainly on vowel insertion patterns per se in which some words always take an epenthetic vowel (e.g., rope $\rightarrow\left[\operatorname{lop}^{\text {hi }}\right]$ ), some never do (e.g., group $\rightarrow[$ kirup $]$ ), and some vary between these two options (e.g., tape $\left.\rightarrow\left[\mathrm{t}^{\mathrm{h}} \operatorname{cip}^{\mathrm{h}}\right] \sim\left[\mathrm{t}^{\mathrm{h}} \operatorname{cip}^{\mathrm{h}} \mathrm{i}\right]\right)$. Rhee \& Choi (2001) conducted a statistical analysis on the frequency of variable vowel epenthesis and Jun (2002) reported on a large-scale experiment involving 260 college students; however, both of these studies simply provided a list of factors affecting the likelihood of vowel insertion while the former relied on standardized written loanword data. Boersma \& Hamann (2009) accounted for the phenomenon in terms of an Optimality-theoretic grammar model. Kwon (2017) deals with inter-speaker variation to see if Korean listeners' experience with English affects online adaptation, which is not directly connected to the main interest of the present study. Importantly, none of these studies have provided a phonetic analysis of Korean speakers' productions. Thus, the contribution of this paper is that it pays close attention to acoustic details of the recipient

\footnotetext{
* Stony Brook University, jungyeon.kim@stonybrook.edu

Received 28 October 2018; Revised 26 November 2018; Accepted 5 December 2018

(C) Copyright 2018 Korean Society of Speech Sciences. This is an Open-Access article distributed under the terms of the Creative Commons Attribution Non-Commercial License (http://creativecommons.org/licenses/by-nc/4.0) which permits unrestricted non-commercial use, distribution, and reproduction in any medium, provided the original work is properly cited.
} 
language, finding an answer to unnecessary repair, which is one of puzzling emergent patterns identified in the literature on loanword phonology.

Among earlier studies on unnecessary adaptations, Kang (2003) claims that this seemingly unmotivated vowel epenthesis is motivated by perceptual similarity between Korean and English forms. Kang discusses several perceptual factors promoting vowel epenthesis following English word-final postvocalic stops. One of those factors is release of final stops. Korean word-final stops are never released (Sohn, 1999), whereas word-final stops in English are variably released (Byrd, 1992; Crystal \& House, 1988). Kang argues that vowel insertion may make the Korean output form perceptually similar to an English final released stop, noting that stop release in English and an epenthetic vowel in Korean are phonetically similar.

Kang (2003) describes vowel insertion pattern in this position based on a survey of loanword list compiled by the National Academy of the Korean Language (1991). Her loanword list contained loanwords from English source words that ended in postvocalic stops. According to her report, the overall frequency of final vowel insertion was $50.3 \%$, that of having no inserted vowel was $43.6 \%$, and that of variable insertion was 6\% (Kang, 2003: 229). However, this result might not reflect the recent tendency of loanwords borrowed from English since her list was based on loanwords gathered from books published in 1990.

The current study has built a new corpus consisting of material complied in more recent publications of the National Academy of the Korean Language $(2001 ; 2002)$. The corpus data is based on 540 Korean loanwords borrowed from English whose source words end in a stop. Out of 540 English words with a final stop, 264 were consistently adapted with final vowel insertion and 214 were consistently adapted without final vowel insertion, while 62 were variably adapted both with and without vowel insertion. That is, the frequency of vowel insertion patterns in the corpus is $49 \%$ for vowel insertion, $40 \%$ for no vowel insertion, and $11 \%$ for optional vowel insertion. This finding shows that vowel insertion is more frequent than lack of insertion, even though final stops are permissible codas in Korean.

The higher frequency of final vowel insertion in Korean loanwords borrowed from English might be attributed to the fact that the corpus focus on English words that have already entered the Korean lexicon. In order to investigate whether Korean speakers really insert a vowel following the English final stop, this study conducted an online production task where Korean participants listened to English nonce words ending in a stop and repeated what they heard. As a control group, English speakers were recruited from the same task. The repetition task was essentially an L2 production experiment. This task was actually about both perception and production since participants first heard and then reproduced what they heard. If release causes them to hear a final vowel, they should produce a final vowel, and an illusory vowel is expected to be reflected in their production. This laboratory adaptation study clearly has an advantage over a production method like a reading task in that the repetition experiment taps into two different levels of perception and production.

Following the completion of the repetition task, to determine whether Korean speakers inserted a vowel after final stops, their productions were analyzed in terms of the duration of noise intervals following the closure of final stops. This experiment can also serve to compare the patterns in integrated loanwords of the corpus to Korean speakers' online production of English nonce words that were completely new to Korean participants.

\section{Method}

\subsection{Stimuli}

Experimental items consisted of 36 English nonce forms: 12 monosyllabic, 12 disyllabic, and 12 trisyllabic forms. English nonce forms consisted of words with a lax pre-final vowel $[\varepsilon]$. The shape of the monosyllabic words was CVC; that of disyllabic words was $\mathrm{C}_{1} \mathrm{~V}_{1} \mathrm{C}_{2} \mathrm{~V}_{2} \mathrm{C}$; and that of trisyllabic words was $\mathrm{C}_{1} \mathrm{~V}_{1} \mathrm{C}_{2} \mathrm{~V}_{2} \mathrm{C}_{3} \mathrm{~V}_{3} \mathrm{C}$. Disyllabic and trisyllabic items had final stressed syllables (e.g., go' zep', 'gomo,zep'). Items varied in terms of three different linguistic factors: (i) release of final stops, i.e., 18 items ending in unreleased stops (e.g., kep', keb') and 18 items ending in released stops (e.g., kep, keb); (ii) voicing of final stops, i.e., 18 items ending in voiceless stops (e.g., kep', kep) and 18 items ending in voiced stops (e.g., keb', keb); and (iii) place of final stops, i.e., 12 items ending in

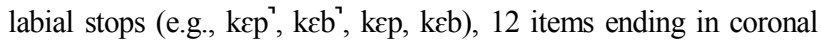

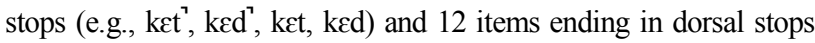

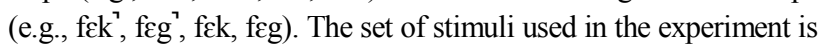
given in Table 1.

Table 1. Test items for the task

\begin{tabular}{|c|c|c|c|}
\hline Release & Voicing & Size & Stimuli \\
\hline \multirow{6}{*}[-\mathrm{rel}]{} & \multirow{3}{*}[-\text{voi}]{} & 1 & $\mathrm{kep}^{\top} \mathrm{k \varepsilon t} \mathrm{t}^{\top} \mathrm{\varepsilon} \mathrm{k}^{\top}$ \\
\hline & & 2 & go'zep’ go'zet' go'zek \\
\hline & & 3 & 'gomo,zep " gomo,zet ' 'gomo,zek \\
\hline & \multirow{3}{*}[+\mathrm{voi}]{} & 1 & $\mathrm{k} \mathrm{b}^{\top} \mathrm{k} \varepsilon \mathrm{d}^{\top} \mathrm{f} \varepsilon \mathrm{g}^{\top}$ \\
\hline & & 2 & go'zeb ' go'zed' go'zeg' \\
\hline & & 3 & 'gomo,zeb 'gomo,zed" 'gomo,zeg' \\
\hline \multirow{6}{*}[+\mathrm{rel}]{} & \multirow{3}{*}[-\mathrm{voi}]{} & 1 & kep ket fek \\
\hline & & 2 & go'zep go'zet go'zek \\
\hline & & 3 & 'gomo,zep 'gomo,zet 'gomo,zek \\
\hline & \multirow{3}{*}{ [+voi $]$} & 1 & $\mathrm{k} \varepsilon b \mathrm{k} \varepsilon \mathrm{d} f \varepsilon g$ \\
\hline & & 2 & go'zeb go'zed go'zeg \\
\hline & & 3 & 'gomo,zeb 'gomo,zed 'gomo,zeg \\
\hline
\end{tabular}

To create the auditory stimuli, a female speaker of American English produced the experimental items. The speaker was a linguist who was able to carefully control release of the English final stop. Praat (Boersma \& Weenink, 2018) was used to check the presence/ absence of release for the auditory stimuli. The speaker recorded the stimuli in a sound-attenuated booth using a Zoom H4n recorded at $44.1 \mathrm{kHz}$ sampling rate (16 bits per sample) and a Shure SM57 unidirectional dynamic microphone.

\subsubsection{Analysis}

All of the auditory stimuli were analyzed to make sure that they had phonetic characteristics related to release and voicing of final stops using Praat: (i) presence/absence of final stop release, (ii) length of final stop release, and (iii) closure voicing length of voiced final stops. All of these acoustic properties were hypothesized to influence vowel insertion of Korean speakers. Specifically, regarding stop release duration, Wilson et al. (2014) suggests that L2 speakers are more likely to interpret longer stop releases as having an epenthetic vowel due to the acoustic similarity between a longer release and a vowel. The duration of closure voicing for voiced 
stops will also help confirm that there is a phonetic difference between voiced vs. voiceless stops in the auditory stimuli.

\subsubsection{Presence/absence of stop release}

Each stimulus classified as having a released final stop contained evidence of visible release on the waveform and spectrogram, and no visible release was observed for stops classified as unreleased. Figures 1 and 2, waveform and spectrogram for the stimuli [kep'] and $[\mathrm{k} \varepsilon \mathrm{p}]$, are representative. All the other stimuli also show similar release or non-release, which is consistent with this classification.

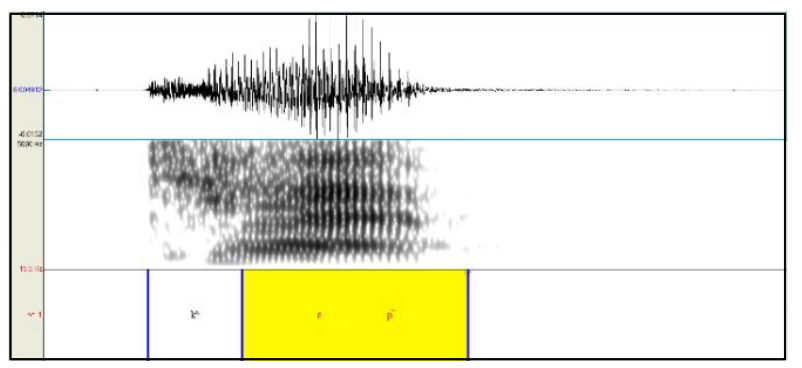

Figure 1. Waveform and spectrogram of $\left[\mathrm{k}^{\mathrm{h}} \varepsilon \mathrm{p}^{\mathrm{h}}\right]$ ending in unreleased $\left[\mathrm{p}^{\mathrm{T}}\right]$.

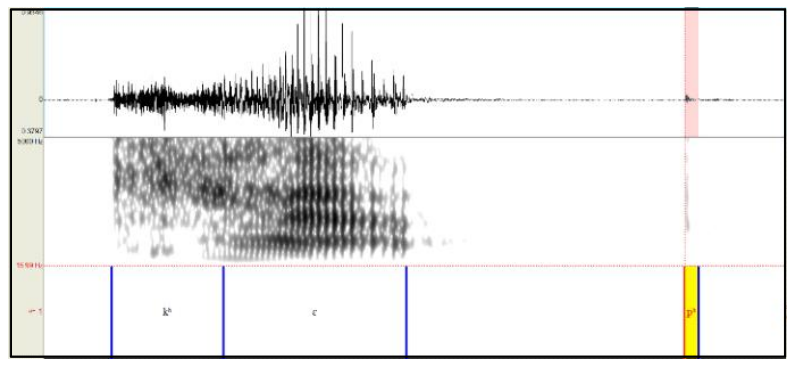

Figure 2. Waveform and spectrogram of $\left[\mathrm{k}^{\mathrm{h}} \varepsilon \mathrm{p}\right]$ ending in released $[\mathrm{p}]$.

\subsubsection{Length of final stop release}

The stop release duration was measured for released final stops. The onset of stop release was defined as the point at which a pulse of acoustic energy for the release of the final stop. The offset of stop release was the point at which acoustic energy of the stop release significantly decreased. As shown in Table 2, the mean duration of stop release was longer for voiceless final stops than for voiced final stops.

Table 2. Mean duration of bursts for released final stops

\begin{tabular}{c|c|c|c|c|c|c}
\hline (ms) & \multicolumn{3}{|c|}{ Voiceless } & \multicolumn{3}{c}{ Voiced } \\
\hline Stops & Lab & Cor & Dor & Lab & Cor & Dor \\
\hline Burst duration & 11 & 15 & 25 & 12 & 15 & 18 \\
\hline Mean & \multicolumn{3}{|c|}{17} & \multicolumn{3}{c}{15} \\
\hline
\end{tabular}

\subsubsection{Closure voicing length}

The stop closure voicing length was measured for released and unreleased voiced final stops. The onset of stop voicing was defined as the point at which acoustic energy of the preceding vowel significantly decreased and there was a change in periodicity that signaled the beginning of a stop closure. The offset of stop voicing during the closure was the point at which acoustic energy and periodicity ceased. The duration of voicing for unreleased and released voiced final stops is given in Tables 3 and 4 . The results for voicing length confirmed that there was an acoustic difference between voiced and voiceless stops in the stimuli.

Table 3. Voicing duration of unleased voiced stops

\begin{tabular}{c|c|c|c}
\hline (ms) & \multicolumn{3}{|c}{ Voiced } \\
\hline Stops & $\mathrm{b}$ & $\mathrm{d}$ & $\mathrm{g}$ \\
\hline Voicing duration & 44 & 52 & 38 \\
\hline Mean & \multicolumn{4}{|c}{45} \\
\hline
\end{tabular}

Table 4. Voicing duration of released voiced stops

\begin{tabular}{c|c|c|c}
\hline (ms) & \multicolumn{3}{|c}{ Voiced } \\
\hline Stops & $\mathrm{b}$ & $\mathrm{d}$ & $\mathrm{g}$ \\
\hline Voicing duration & 80 & 48 & 53 \\
\hline Mean & \multicolumn{3}{|c}{60} \\
\hline
\end{tabular}

\subsection{Participants}

Ten Korean and ten English native speakers participated in the experiment. The Korean participants, five males and five females (Mean age=23.9, $\mathrm{SD}=2.0$ ), were recruited from Sogang University in Seoul, Korea. Their average age of first exposure to English study was 10.2 years $(\mathrm{SD}=1.9)$. No participants had lived in an English-speaking country or majored in English at the time of the task. As a control group, ten native speakers of American English recruited from Stony Brook University participated in the repetition experiment, five males and five females (Mean age $=26.3, \mathrm{SD}=4.3$ ). They were monolingual and had no experience with Korean. None of the participants reported any hearing or speech disorders. All were paid for their participation after completing the experiment.

\subsection{Procedure}

Participants were asked to listen to auditory stimuli and to repeat what they heard through a laptop computer. They were given no orthographic or other information but only aural information using a headphone. Each frame consisted of repetition of a stimulus followed by the phrase "Please repeat". After this, participants were given three seconds to produce the stimulus. The participants were familiarized with the experimental task by taking a practice trial round with a couple of words that were not included in the test items. The recording of the Korean group was conducted in a sound-attenuated booth in the English Department at Sogang University, and that of the English group in the Linguistics Department at Stony Brook University. Both recordings were done using a Shure SM57 microphone and a Zoom H4n recorder at 44.1 $\mathrm{kHz}$ sampling rate.

\subsection{Predictions}

The perceptual similarity approach, proposed by Kang (2003) following Steriade (2001), assumes that Korean speakers accurately perceive the English forms, but they insert a vowel in their production to maintain perceptual similarity between the English and Korean forms. Thus, this approach predicts for the production experiment that Korean speakers will produce the English final stop as a stop followed by a vowel although they correctly perceive the stop as a final consonant.

Producing $\mathrm{C}$ as $\mathrm{CV}$ should result in noise intervals after the final consonant that are longer than those associated with producing $\mathrm{C}$ as $\mathrm{C}$ even where $\mathrm{C}$ is released because producing $\mathrm{C}$ as $\mathrm{C}$ involves transient and frication of the stop while producing $\mathrm{C}$ as $\mathrm{CV}$ involves aspiration and onset of voicing following transient and frication. As 
will be discussed in the following section, noise intervals were defined as every noise made following the closure of final stops. For the production task, Korean speakers are predicted to produce stronger noise intervals than English speakers, who never insert a vowel after the final stop and simply release the stop. The vowel that is expected to be inserted by Korean speakers is predicted to be perceived as an epenthetic vowel by English listeners. The predictions given in (1) are tested by comparing the productions of Korean and English speakers and investigating the noise intervals of Korean speakers.

\section{(1) Predictions for the production experiment}

a. Korean speakers will produce significantly longer noise intervals after English final stops than English speakers.

b. The longer noise intervals of Korean speakers will be perceived by English listeners as an epenthetic vowel.

In the following section, I discuss the noise intervals after the stop closure of the final stops and check if noise intervals produced by Korean speakers are longer when compared to those of English speakers.

\subsection{Noise intervals of final stops}

The productions of ten Korean and ten English speakers were measured using Praat (Boersma \& Weenink, 2018). For each speaker, a noise interval following the closure of final stops was measured. I first discuss the definition of burst noise in the description of noise events of syllable-initial stops and turn to "noise intervals" that the current study addresses. Kent \& Read (2002) describes a sequence of acoustic events associated with progression from a word-initial stop to a vowel: transient, frication, aspiration, and voicing. On the release, a pulse of energy is created as the air escapes. This plosion is called a transient because of its brevity and momentary character although this terminology is not widely used (Kent \& Read, 2002: 141). The transient is one of the shortest acoustic events in speech, no longer than 5 to $40 \mathrm{~ms}$ in duration. It is followed by frication which is a turbulence noise created as the oral constriction is gradually released. Following the transient and frication, aspiration occurs in the case of word-initial stops. Aspiration is followed by onset of voicing where vocal fold vibration for the vowel is initiated.

Unlike word-initial stop consonants, stops in word-final position, which are the focus of this study, may be either released or unreleased. When the stop is not released, the closure is maintained until after the utterance is finished and no burst such as transient and frication occurs. On the other hand, when the final stop is released, transient and frication appear, as in word-initial stops. This is where we expect to see differences between the productions of English and Korean speakers. English speakers who release the final stops should produce only transient and frication; however, Korean speakers are predicted to insert a vowel following the final released stop and hence produce transient, frication, aspiration and voicing of an epenthetic vowel, just like in word-initial stops. Thus, the duration of noise intervals after the stop closure is expected to be much longer in the productions of Korean speakers compared to those of English speakers since noise intervals of Korean speakers are predicted to include all of the acoustic events from transient through onset of voicing.

Measurements were conducted for items ending in released stops.
The onset of noise intervals was defined as the point at which there was a pulse of acoustic energy for the release of the final stop. The offset of noise intervals was the point at which frication of the final stop significantly decreased. Here, only correct productions were included in the analysis, and error responses were excluded. Examples of incorrect responses were devoicing (b, d, g $\rightarrow p, t, k)$, voicing $(p, t, k \rightarrow b, d, g)$, and fricativization $(b \rightarrow v)$. Figures 3 through 6 are representative samples of how voiceless and voiced final stops were segmented.

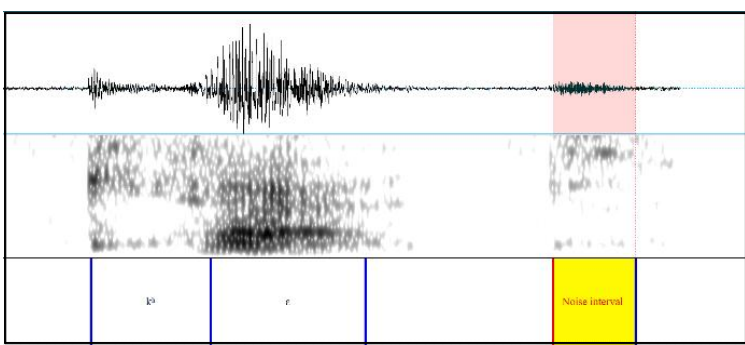

Figure 3. Segmentation showing noise interval after $[\mathrm{t}]$ produced by English female speaker (stimulus item: $\left[\mathrm{k}^{\mathrm{h}} \mathrm{ct}\right]$ ).

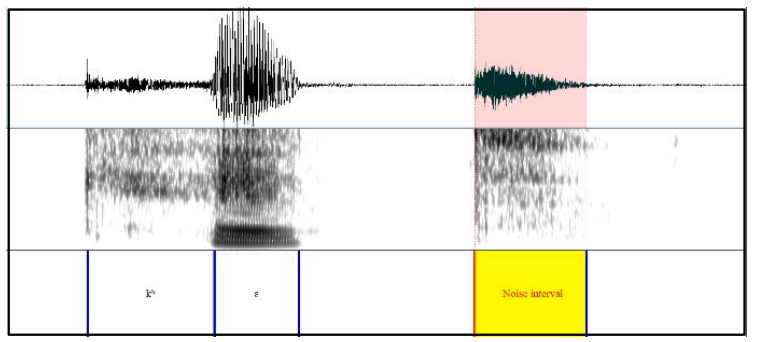

Figure 4. Segmentation showing noise interval after $[\mathrm{t}]$ produced by Korean female speaker (stimulus item: $\left[\mathrm{k}^{\mathrm{h}} \mathrm{ct}\right]$ ).

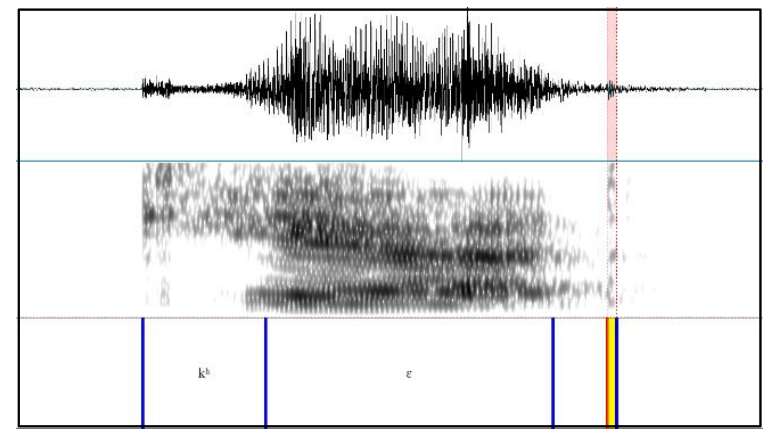

Figure 5. Segmentation showing noise interval after [d] produced by English female speaker (stimulus item: $\left[\mathrm{k}^{\mathrm{h}} \varepsilon \mathrm{d}\right]$ ).

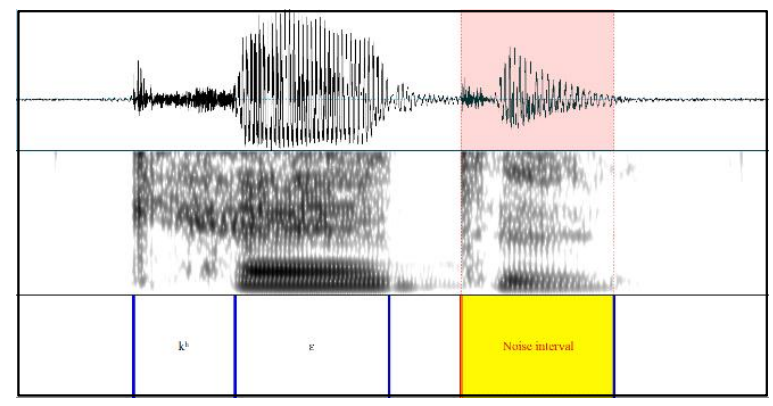

Figure 6. Segmentation showing noise interval after [d] produced by Korean female speaker (stimulus item: $\left[\mathrm{k}^{\mathrm{h}} \varepsilon \mathrm{d}\right]$ ). 


\section{Results}

A statistical analysis was conducted using a linear mixed-effects model (Baayen et al., 2008), which examines the difference in noise intervals between Korean and English groups. The analysis was carried out using the lmer function in the lme4 package (Bates et al., 2015) for $R$ (R Core Team, 2017). The dependent variable was the duration of noise intervals following the final stops. A fixed effect predictor was Group (Korean or English) and it was coded using deviation coding (English $=-0.5$; Korean $=0.5$ ). Random effects include participants and items. Random intercept model converged and only a random intercept was included for both participants and items.

The statistical model confirmed that Korean participants had significantly longer noise intervals than English participants $(\beta=0.129$, $S E=0.009, t=13.81, p<0.001)$, which was consistent with the prediction about differences in noise intervals after stop closure of final stops between the two speaker groups. Table 5 shows that the mean duration of noise intervals for Korean speakers was $188 \mathrm{~ms}$, while that of English speakers was $53 \mathrm{~ms}$. Male speakers produced longer noise intervals than female speakers in both Korean and English participant groups.

Table 5. Mean duration of noise intervals produced by Korean and English speakers

\begin{tabular}{|c|c|c|c|}
\hline Group & Gender & Participant & Mean duration (ms) \\
\hline \multirow{13}{*}{ Korean } & \multirow{6}{*}{ Female } & S1 & 222 \\
\hline & & $\mathrm{S} 2$ & 183 \\
\hline & & $\mathrm{S} 3$ & 136 \\
\hline & & S4 & 198 \\
\hline & & S5 & 169 \\
\hline & & F. mean & 182 \\
\hline & \multirow{6}{*}{ Male } & S6 & 176 \\
\hline & & S7 & 197 \\
\hline & & S8 & 178 \\
\hline & & S9 & 131 \\
\hline & & S10 & 288 \\
\hline & & M. mean & 194 \\
\hline & \multicolumn{2}{|c|}{ Total mean } & $188(\mathrm{SD}=44.6)$ \\
\hline \multirow{13}{*}{ English } & \multirow{6}{*}{ Female } & $\mathrm{S} 1$ & 73 \\
\hline & & S2 & 56 \\
\hline & & S3 & 33 \\
\hline & & $\mathrm{S} 4$ & 28 \\
\hline & & S5 & 50 \\
\hline & & F. mean & 48 \\
\hline & \multirow{6}{*}{ Male } & S6 & 49 \\
\hline & & S7 & 35 \\
\hline & & S8 & 63 \\
\hline & & S9 & 59 \\
\hline & & $\mathrm{S} 10$ & 87 \\
\hline & & M. mean & 59 \\
\hline & \multicolumn{2}{|c|}{ Total mean } & $53(\mathrm{SD}=18.5)$ \\
\hline
\end{tabular}

We now turn to the next question: is this longer noise interval of Korean speakers heard as an epenthetic vowel by English listeners? This question is important in deciding whether the Korean participants were producing final released stops or whether they were actually inserting a vowel after the final stop. In the following section, I discuss how English speakers transcribed the productions of Korean participants to determine whether English speakers actually perceive productions of Korean speakers as having an epenthetic vowel.

\subsection{Epenthetic vowels}

To see if the stronger noise intervals found in Korean speakers' productions were heard as epenthetic vowels by English listeners, the productions of Korean speakers were transcribed by two phonetically trained native English speakers. ${ }^{1}$ ) Transcribers were asked to decide whether the Korean participants were producing a vowel word-finally or whether they were just releasing the word-final stop. Forms on which the two transcribers did not agree were transcribed by a third transcriber. The results of the transcriptions showed that only $3 \%$ of total correct productions were heard as an epenthetic vowel, i.e., 8 responses out of 231 were perceived as having a final vowel. As in the waveform analysis of noise intervals, only correct responses were included in the transcriptions; responses that were incorrectly produced were excluded from the analysis, i.e., voiced segments as voiceless, voiceless segments as voiced, or stops produced as fricatives. Total correct production samples of ten Korean participants were 231 out of 360 ( 36 stimuli $\times 10$ participants), where they heard 180 items ending in released stops.

Table 6 gives the numbers of tokens perceived as having an epenthetic vowel for each Korean participant and mean duration of final vowels for tokens heard as CV; Figure 7 gives the percent of tokens perceived as $\mathrm{CV}$. As shown in the figure, even the highest CV rate (S5) was only $13 \%$ and six participants (S1, S2, S3, S4, S7, and $\mathrm{S} 10$ ) had no final vowel transcribed in any of their productions $(\mathrm{CV}=0 \%$ ). Although the $\mathrm{CV}$ rate of male speakers was higher than that of female speakers, the mean rate for male speakers was still below $5 \%$.

The first prediction for the production task was confirmedKorean speakers produced significantly longer noise intervals after English final stops than English speakers-on the other hand, the second prediction was not confirmed: the longer noise intervals of Korean participants were not perceived by English listeners as an epenthetic vowel.

\section{Discussion}

The fact that more than $95 \%$ of Korean participants' productions were perceived to include no epenthetic vowel was not consistent with the loanword data, where $49 \%$ of words showed vowel insertion. The result of the production task was also inconsistent with the prediction of the perceptual similarity approach. This view predicted that because Korean speakers correctly perceive an English final released stop as a final consonant, they would insert a vowel to make the English sound more similar to the Korean sound.

1 Different types of methodology may be used to analyze phonetic data. In the current study, transcription method is used to judge the production of Korean speakers since the perception of English listeners can provide the crucial fact for the purpose of this study. I also conducted waveform analysis of epenthetic vowels produced by the Korean participants; the vowels that were clearly noticeable on the waveform were $4 \%$ of total productions, which is consistent with the transcription results where English transcribers judged that 3\% included final vowel insertion. 
Table 6. Number of tokens perceived as final vowel (CV) vs. no final vowel $(\mathrm{C})$ and mean vowel length of tokens heard as $\mathrm{CV}$

\begin{tabular}{|c|c|c|c|c|c|}
\hline Gender & Participant & $\mathrm{CV}$ & $\mathrm{C}$ & Total & Mean V length (ms) \\
\hline \multirow{5}{*}{ Female } & S1 & 0 & 23 & 23 & 0 \\
\hline & $\mathrm{S} 2$ & 0 & 27 & 27 & 0 \\
\hline & S3 & 0 & 27 & 27 & 0 \\
\hline & S4 & 0 & 23 & 23 & 0 \\
\hline & S5 & 3 & 21 & 24 & 101 \\
\hline \multicolumn{2}{|c|}{ Female total } & 3 & 121 & 124 & 101 \\
\hline \multirow{5}{*}{ Male } & S6 & 2 & 17 & 19 & 86 \\
\hline & S7 & 0 & 22 & 22 & 0 \\
\hline & S8 & 2 & 22 & 24 & 70 \\
\hline & S9 & 1 & 22 & 23 & 109 \\
\hline & $\mathrm{S} 10$ & 0 & 19 & 19 & 0 \\
\hline \multicolumn{2}{|c|}{ Male total } & 5 & 102 & 107 & 84 \\
\hline
\end{tabular}

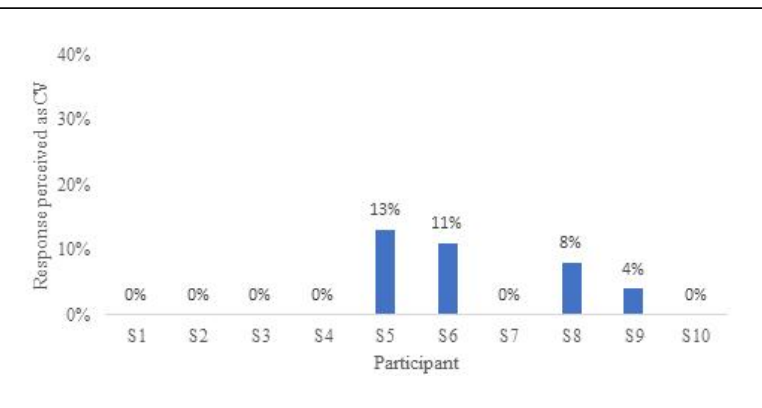

Figure 7. Percent of tokens perceived as final vowel (CV) for each Korean participant (Error bars indicate $95 \%$ confidence intervals).

The difference in the results between the loanword analysis and the production task might have arisen from the fact that the corpus study was based on written integrated loanwords. Korean loans written in books tend to observe the guidelines of the National Academy of the Korean Language, where vowel insertion is required when certain conditions are satisfied. For example, the guidelines indicate that a word-final voiced stop shall be written with [i] and that a word-final voiceless stop after a lax vowel shall be written as a coda while one after a tense vowel shall be followed by [i] (http://www.korean.go.kr/). However, in the production experiment, Korean participants were asked to immediately repeat a series of English nonce words. The results from the online adaptation would suggest that speakers were trying to imitate the release of the English final stop in an exaggerated manner by the longer noise intervals after the stop closure. The longer noise interval did not turn out to be identified as an epenthetic vowel by English listeners. That is, the productions of Korean participants as perceived by English speakers almost never included final vowel insertion. Therefore, the results of the production task were not predicted by the perceptual similarity approach.

There are other possible explanations for this unexpected finding. First, it is possible that the nature of the task was simply too different from actual loan adaptation, where listeners might have more competing demands on their attention. Here in the production task, participants heard and repeated a single word, whereas in loanword adaptation listeners might hear different words in different contexts while they are doing real processing and therefore be more likely to misperceive. It is also possible that Korean speakers did intend to produce a final vowel, but that English listeners failed to hear this vowel because Korean high vowels tend to be devoiced after aspirated stops (Jun \& Beckman, 1994). The waveform analysis of participants' productions showed that some of their final vowels really tended to be devoiced following released stops, which suggests that English listeners might have perceived the Korean devoiced vowel as consonant release.

The latter possibility will be pursued in future research by examining the phonetic properties of epenthetic vowels in Korean and comparing them with those of lexical vowels. If it turns out that epenthetic vowels are acoustically different from lexical vowels and that they are phonetically close to devoiced vowels, that would account for the finding that English transcribers perceived Koreans' strong noise intervals as stop release. Moreover, the mismatch between the loanword patterns and the production experiment raises the question of what actually happens in perception of English forms by Korean speakers. As the perceptual similarity approach, Korean listeners might accurately perceive an English final released stop as a final consonant. On the other hand, they might incorrectly perceive it as a stop followed by a vowel (misperception approach, Boersma \& Hamann, 2009; Broselow, 2009; de Jong \& Park, 2012; Dupoux et al., 1999; Kwon, 2017; Silverman, 1992; among others). I will conduct a perception experiment in future study to carry on a discussion about the two different approaches and to investigate the perception of L2 speakers.

\section{References}

Baayen, R. H., Davidson, D. J., \& Bates, D. M. (2008). Mixed-effects modeling with crossed random effects for subjects and items. Journal of Memory and Language, 59(4), 390-412.

Bates, D., Maechler, M., Bolker, B., \& Walker, S. (2015). Fitting linear mixed-effects models using lme4. Journal of Statistical Software, 67(1), 1-48.

Boersma, P., \& Hamann, S. (2009). Loanword adaptation as firstlanguage phonological perception. A. Calabrese, \& W. Wetzels (Eds.), Loanword phonology (pp. 11-58). Amsterdam/ Philadelphia: John Benjamins Publishing Company.

Boersma, P., \& Weenink, D. (2018). Praat: doing phonetics by computer. Version 6.0.43. Retrieved from http://www.praat.org/ on September 8, 2018.

Broselow, E. (2009). Stress adaptation in loanword phonology: perception and learnability. P. Boersma, \& S. Hamann (Eds.), Phonology in perception (pp. 191-234). Berlin and New York: Mouton de Gruyter.

Byrd, D. (1992). A note on English sentence-final stops. UCLA Working Papers in Phonetics, 81, 37-38.

Crystal, T. H., \& House, A. S. (1988). The duration of AmericanEnglish stop consonants: An overview. Journal of Phonetics, 16(3), 285-294.

de Jong, K., \& Park, H. (2012). Vowel epenthesis and segment identity in Korean learners of English. Studies in Second Language Acquisition, 34(1), 127-155.

Dupoux, E., Kakehi, K., Hirose, Y., Pallier, C., \& Mehler, J. (1999). Epenthetic vowels in Japanese: A perceptual illusion? Journal of Experimental Psychology: Human Perception and Performance, 25(6), 1568-1578.

Golston, C., \& Yang, P. (2001). White Hmong loanword phonology. C. Féry, A. Green, \& R. R. van de Vijver (Eds.), Proceedings of HILP, 5 (pp. 40-57). Potsdam: University of Potsdam.

Jun, E. (2002). An experimental study of the effect of release of 
English syllable final stops on vowel epenthesis in English loanwords. Studies in Phonetics, Phonology and Morphology, 8, 117-134. (전은 (2002). 영어 차용어 음절 말 폐쇄음의 파열 여부 와 모음삽입에 관한 실험적 연구. 음성.음운 형태론 연구, 8 , 117-134.)

Jun, S. A., \& Beckman, M. E. (1994). Distribution of devoiced high vowels in Korean. Proceedings of the $3^{\text {rd }}$ International Conference on Spoken Language Processing (pp. 479-482).

Kang, Y. (2003). Perceptual similarity in loanword adaptation: English postvocalic word-final stops in Korean. Phonology, 20(2), 219-273.

Kent, R., \& Read, C. (2002). The acoustic analysis of speech. San Diego: Singular Press.

Koo, B.-K. (2010). Evaluation for the influence of loanword orthography. Seoul: Kwuklipkwukewen. (구본관 (2010). 외래어 표기 규범 영향 평가. 서울: 국립국어원.)

Kwon, H. (2017). Language experience, speech perception and loanword adaptation: variable adaptation of English word-final plosives into Korean. Journal of Phonetics, 60, 1-19.

Peperkamp, S. (2005). A psycholinguistic theory of loanword adaptations. M. Ettlinger, N. Fleischer, \& M. Park-Doob (Eds.), Proceedings of the $30^{\text {th }}$ Annual Meeting of the Berkeley Linguistics Society, Berkeley (pp. 341-352), CA: Berkeley Linguistics Society

R Core Team (2017). R: A language and environment for statistical computing. R Foundation for Statistical Computing, Version 3.5.1. Retrieved from http://www.r-project.org on January 2, 2018.

Rhee, S. J., \& Choi, Y. K. (2001). A statistical observation of vowel insertion in English loanwords in Korean and its significance. Studies in Phonetics, Phonolgy and Morphology, 7, 153-176. (이 석재·최유경 (2001). 영어 차용어의 모음 삽입에 대한 통계관 찰과 그 의의. 음성.음운 형태론 연구, 7, 153-176.)

Silverman, D. (1992). Multiple scansions in loanword phonology: Evidence from Cantonese. Phonology, 9(2), 289-328.

Sohn, H. M. (1999). The Korean language. Cambridge: Cambridge University Press.

Steriade, D. (2001). Directional asymmetries in place assimilation: A perceptual account. E. Hume, \& K. Johnson (Eds.), The role of speech perception in phonology (pp. 219-250). San Diego, CA, US: Academic Press.

The National Academy of the Korean Language (1991). Survey of the state of loanword usage: 1990. Seoul: Kwuklipkwukewen. (국립 국어원 (1991). 외래어 사용 실태 조사. 1990년도. 서울: 국립국 어원.)

The National Academy of the Korean Language (2001). Survey of pronunciation of loanwords. Seoul: Kwuklipkwukewen. (국립국 어원 (2001). 외래어 발음 실태 조사. 서울: 국립국어원.)

The National Academy of the Korean Language (2002). Guidelines for loanword orthography. Seoul: Kwuklipkwukewen. (국립국어 원 (2002). 외래어 표기 용례집. 서울: 국립국어원.)

The National Academy of the Korean Language (2007). Recognition, understanding, usage and attitude to loanwords. Seoul: Kwuklipkwukewen. (국립국어원 (2007). 외래어 인지도·이해 도·사용도 및 태도조사. 서울: 국립국어원.)

Wilson, C., Davidson, L., \& Martin, S. (2014). Effects of acousticphonetic detail on cross-language speech production. Journal of Memory and Language, 77, 1-24.

Yi, H.-S. (2007). A survey on the usage of loanwords and foreign words and on the acceptance of refined words. Seoul: Kwuklipkwukewen. (이홍식 (2007). 외래어·외국어 사용 및 순
화어 수용 실태조사. 서울: 국립국어원.)

\section{- Kim, Jungyeon}

Ph.D. alumna, Department of Linguistics

Stony Brook University

100 Nicolls Road, Stony Brook

NY 11794, USA

Tel: 1-631-632-7774

Email: jungyeon.kim@stonybrook.edu

Fields of interest: Phonetics, Phonology 